\title{
Is Self-medication with over the Counter Abortion Pills Really Safe? An Experience at a Tertiary Care Centre
}

\author{
${ }^{1}$ Renu Gupta, ${ }^{2}$ Pavika Lal, ${ }^{3}$ Shaily Agarwal, ${ }^{4}$ Neena Gupta, ${ }^{5}$ Ruchika Tahilyani, ${ }^{6}$ Namrata Dawani
}

\section{ABSTRACT}

Objectives: To study the clinical profile and outcome of patients in terms of maternal morbidity and mortality at a tertiary care center following self-medication of over the counter MTP pills.

Materials and methods: This is prospective observational study conducted at Upper India Sugar Exchange Maternity Hospital, Ganesh Shankar Vidyarthi Memorial Medical College (GSVMMC or GSVM) Kanpur between January 2016 to June 2017 for 18 months. A total of 587 women were enrolled in our study. Data were recorded with respect to socioeconomic status, clinical presentation and various adverse consequences in the study population. Analysis of a number of blood transfusions, sepsis, shock, anemia, any surgical interventions was done was noted. A questionnaire was prepared in the local language to know the source of information regarding the abortion pill and to analyze the reasons for self-medication.

Results: Majority of women were in totoal 30 to 40 yrs age group $(54.51 \%)$ and were married $(81.43 \%) .52 .63 \%$ of women did not confirm their pregnancy either by a urine pregnancy test and or by ultrasound self-medication. Total $32.02 \%$ had consumed the abortion pill $>9$ weeks period of gestation. The maximum number of women had chosen this method to avoid surgical intervention while $89.26 \%$ of women used it due to its easy availability without a prescription. The most common complication was anemia (92.5\%) followed by sepsis.

Conclusion: Easy availability of over the counter medical abortion pills without prescription is a serious threat as it leads to grave consequences of maternal health and significantly contributes to unsafe abortion. Healthcare facilities should undertake measures to reduce the indiscriminate use of medical abortion pills and safeguard the health of the mother.

Keywords: Medical abortion, Over the counter, Self-medication, Unsafe abortions.

How to cite this article: Gupta R, Lal P, Agarwal S, Gupta N, TahiIyani R, Dawani N. Is Self-medication with over the Counter Abortion Pills Really Safe? An Experience at a Tertiary Care Centre, J South Asian Feder Obst Gynae 2018;10(3):227-230.

Source of support: Nil

Conflict of interest: None

\footnotetext{
${ }^{1,3}$ Associate Professor, ${ }^{2}$ Assistant Professor, ${ }^{4}$ Professor,

5,6 Junior Resident

1-6Department of Obstetrics and Gynaecology, Ganesh Shankar Vidyarthi Memorial Medical College, Kanpur, India
}

Corresponding Author: Pavika Lal, Assistant Professor, Department of Obstetrics and Gynaecology, Ganesh Shankar Vidyarthi Memorial Medical College, Kanpur, India, Mobile: +91945360409, e-mail: Lalpavika@gmail.com
Date of received: $15 / 5 / 2017$

Date of acceptance: 20/10/2018

Date of publication: December 2018

\section{INTRODUCTION}

Unsafe abortion occurs when a pregnancy is terminated either by persons lacking the necessary skills or in an environment that does not confirm the minimal medical standards or both. ${ }^{1}$

According to first national study of the incidence of abortion and unintended pregnancy in India, an estimated 15.6 million abortions were performed in the country in 2015. This translates to an abortion rate of 47 per 1000 women aged 15 to 49 years, which is similar to abortion rate in the neighboring South Asian countries. ${ }^{2}$

The world health organization $(\mathrm{WHO})$ recommendations on medical abortion are restricted to early first trimester (up to 63 days since first day of last menstrual period). ${ }^{3}$ Food and Drug Administration (FDA or USFDA) has approved antiprogesterone drugs such as mifepristone RU486, prostaglandins like misoprostol for medical abortions. As per MTP act of INDIA, this method can only be administered by gynecologists and registered medical practitioners recognized for performing MTPs up to 49 days since the first day of the last menstrual period. Despite this, it has been perceived by the society that despite the liberalization of the MTP act and the surprising data of unsafe abortion, the perception among the general population that medical abortions are an extremely safe alternative even in the hands of untrained personnel.

Women, including adolescents with unintended pregnancies, resort to unsafe abortions due to various barriers including restrictive laws and poor availability of services. Therefore the aim was to study the sociodemographic profile along with the maternal morbidity and mortality with the unsupervised self-medication of medical abortion pills. The study also highlights the reason for seeking over the counter abortion pills without prescription among the general female population.

\section{MATERIALS AND METHODS}

This was a prospective observational study conducted at Department of Obstetrics and Gynecology Upper India 
Table 1: Socio demographic profile of the study population

\begin{tabular}{|c|c|c|c|}
\hline & & No. & $\%$ \\
\hline \multirow[t]{4}{*}{ 1. Age distribution (Yrs) } & $<20$ & 53 & 9.02 \\
\hline & $21-30$ & 187 & 31.85 \\
\hline & $30-40$ & 320 & 54.51 \\
\hline & $>40$ & 27 & 4.59 \\
\hline \multirow[t]{2}{*}{ 2. Marital status } & Married & 478 & 81.43 \\
\hline & Unmarried & 109 & 18.56 \\
\hline \multirow[t]{3}{*}{ 3. Parity } & G1 & 157 & 26.74 \\
\hline & G2 & 240 & 40.88 \\
\hline & $>\mathrm{G} 3$ & 190 & 32.36 \\
\hline \multirow[t]{2}{*}{ 4. Residence } & Rural & 256 & 43.61 \\
\hline & Urban & 331 & 56.38 \\
\hline \multirow[t]{4}{*}{ 5. Socio-economic status } & Upper & 34 & 5.79 \\
\hline & Middle & 165 & 28.10 \\
\hline & Lower & 388 & 66.09 \\
\hline & Total & 587 & 100 \\
\hline
\end{tabular}

Sugar Exchange Maternity Hospital, GSVM Medical College Kanpur, between January 2016 to June 2017 for 18 months. All 587 women who reported to our hospital after self-medication of abortion pills (purchased over the counter by a self/family member without a prescription) were enrolled in our study. By self-medication we mean these pregnant women had no medical consultation with a registered medical practitioner and has taken abortion pills which was purchased from the pharmacy without any prescription either by self or by some close relative. A total number of 216 women who have consumed MTP pill after consulting gynecologists were excluded from the study.

After written and informed consent, on admission, detailed history regarding previous pregnancies, gestational age at which MTP pill was taken, a method of confirmation of pregnancy and presenting complaints along with complications if any was noted. A queissionare in simple local language was given to all the women at the time of the first contact to inquire about the source of information of MTP pills and their reasons for using it without prescription.

A complete systematic and gynecological examination were done in all the women. The degree of pallor, fever, presence or absence of signs of shock noted. Urine specific gravity (USG) examination was done in every patient for the presence or absence of retained products of conception, incomplete, complete, missed, failed abortion rupture, ectopic pregnancy. A complete blood count along with routine investigations was done as and when required. Data were also recorded as per intensive care unit admissions, need for blood transfusions and maternal deaths.
Table 2: Method of confirmation of pregnancy and period of gestation at self-medication of MTP pill

\begin{tabular}{llll}
\hline & & No. & $\%$ \\
\hline $\begin{array}{l}\text { Confirmation of } \\
\text { pregnancy }\end{array}$ & $\begin{array}{l}\text { Missed } \\
\text { period }\end{array}$ & 278 & 47.35 \\
& $\begin{array}{l}\text { Missed } \\
\text { period+ urine } \\
\text { pregnancy } \\
\text { test }\end{array}$ & 254 & 43.27 \\
& Unmarried & 109 & 18.56 \\
& Ultrasound & 55 & 9.36 \\
\hline Period of gestation & $<7$ weeks & 203 & 34.58 \\
& $7-9$ weeks & 196 & 33.39 \\
& $9-12$ weeks & 104 & 17.71 \\
& $>12$ weeks & 84 & 14.31 \\
\cline { 2 - 4 } & Total & 587 & 100 \\
\hline
\end{tabular}

\section{STATISTICAL METHODS}

Appropriate statistical analytical tools like MS Excel and Statistical Package for the Social Sciences (SPSS) version 20, were used for data analysis and interpretation.

\section{RESULTS}

A total of 587 cases were studied. Majority $86.36 \%$ of women were in 20 to 40 years age group which is the reproductive span of a women's life and $81.43 \%$ were married. In our study population, $40.88 \%$ were the second gravida as compared to prime $26.74 \%$. Majority of women belonged to the lower socio-economic status of the society $(66.09 \%)$, and more than half of our study population were residing in urban areas (Table 1).

As shown in Table 2, $47.35 \%$ of women confirmed their pregnancy neither by urine pregnancy test nor by ultrasound prior to self-medication. Only $33.58 \%$ of women had the abortion pill at $<7$ weeks gestation while $32.07 \%$ took it at $>9$ weeks period of gestation.

In our study population the majority of women $(65.75 \%)$ husband or any close relative informed them about the MTP pills. A maximum number of women $(82.11 \%)$ chose this method to avoid surgical intervention while $89.26 \%$ of women used it due to its easy availability without a prescription (Table 3).

Excessive/irregular bleeding (59.96\%) was the most common symptom presenting complaint followed by pain in the lower abdomen (25.55\%) (Table 4).

Complications developed at or after admission are shown in Table 5 . A total of $33.56 \%$ of women were severely anemic required a blood transfusion. Women (3.9\%) developed shock required intensive care unit admission. Among seven maternal deaths, four were due to hemorrhagic 
Table 3: Reason for self-medication and source of information regarding the MTP pill

\begin{tabular}{|c|c|c|}
\hline A) Reasons & No. & $\%$ \\
\hline 1. Reluctance for contraception & 274 & 46.67 \\
\hline $\begin{array}{l}\text { 2. Surgical intervention } \\
\text { apprehension }\end{array}$ & 482 & 82.11 \\
\hline $\begin{array}{l}\text { 3. Considered to be a safe } \\
\text { method }\end{array}$ & 383 & 65.24 \\
\hline $\begin{array}{l}\text { 4. Easily available without } \\
\text { prescription }\end{array}$ & 524 & 89.26 \\
\hline $\begin{array}{l}\text { 5. Apprehension to visit a doctor/ } \\
\text { hospital }\end{array}$ & 343 & 58.43 \\
\hline 6. As a method of spacing & 83 & 14.13 \\
\hline B) Source of information & No. & $\%$ \\
\hline 1. Husband/relative & 386 & 65.75 \\
\hline 2. Friends & 172 & 29.30 \\
\hline 3. Others & 29 & 4.94 \\
\hline
\end{tabular}

shock and one due to disseminated intravascular coagulation and two due to septicemic shock. Ectopic pregnancy may remain under diagnosed with potentially serious consequences in patients who have taken medical abortion without prior confirmation of intrauterine gestation. ${ }^{4}$

\section{DISCUSSION}

All women enrolled in this study easily purchased the drug from local pharmaceutical shops without any supervised prescription. The administration of the drug was not according to the recommended schedule in most of the patients.

According to WHO, up to 9 weeks period of gestation, $200 \mathrm{mg}$ of Tablet Mifepristone orally followed 24-8 hours by Tablet Misoprostol 800 mcg buccally, sublingually, or vaginally for one dose.

In our study, the maximum number of patients belonged to 20 to 40 years age group and were second gravida residing in areas belonging to the lower socioeconomic class. These revealed the fact that many women used medical abortion were second gravida and had conceived during lactational amenorrhoea and they did not want the second child too early. They had the firm belief that during the lactation period, the conception does not occur. Therefore they need not require any contraceptive method for spacing. The $18.56 \%$ in our study were unmarried who had the belief that MTP pill consumption gets rid of the unwanted pregnancy without having to visit a clinician which may result in public disgrace. Medical abortion is definitely a safer and a better option, but in developed countries, its widespread use has led to partial or septic abortion thereby increasing maternal morbidity and mortality. ${ }^{5}$ In our study, most of the patients who took MTP kit had amenorrhoea of 2
Table 4: Clinical presentation of the study population at the time of admission

\begin{tabular}{lll}
\hline Clinical features & No. & $\%$ \\
\hline 1. Excessive/irregular bleeding & 352 & 59.96 \\
2. Pain in lower abdomen & 150 & 25.55 \\
3. Fever with chills & 39 & 6.64 \\
4. Shock (hypotensive/septic) & 46 & 7.83 \\
\hline Total & 587 & 100 \\
\hline
\end{tabular}

months, and they took MTP kit without the USG documentation for the localization of pregnancy. Many females had the misconception that the abortion pill can be taken at any time irrespective of gestational age and also unaware of the possible serious lifethreatening complications.

Similar findings were reported by Thacker et al. ${ }^{6}$ In our study husband/relatives were the main source of information on the advice of which the patient took the MTP kit. The major reason behind the intake of MTP kit by our patient was that it was easily accessible at the local pharmaceutical shops without any prescription and also to avoid visiting a doctor and any surgical intervention if needed. Only 216 (26.89\%) women had a medical abortion had under medical supervision against $587(73.10 \%)$ who took the drug without a prescription. This strikingly significant difference compelled us to form a questionnaire in simple local language to inquire about the reason behind the rampant use of medical abortion in the general population. None of the studies so far probed the reason behind such higher usage of the medical abortion. Lack of awareness about the potential adverse effects of MTP pills and their easy over the illegal counter availability facilitates such kind of usage.

Thacker reported majority of patients presented with excessive/irregular bleeding ( $59.96 \%$ ) followed by pain lower abdomen (25.55\%). Similar findings were noted in Sarojini et al. ${ }^{7}$ The major complication in our study was anemia of moderate to a severe degree $(92.5 \%)$. Patients who presented with profuse bleeding were managed by immediate surgical evacuation whereas when bleeding was minimal and with USG showing minimal products

Table 5: Complications among the study population

\begin{tabular}{lll}
\hline Clinical features & No. & $\%$ \\
\hline 1. Moderate anemia & 346 & 58.94 \\
$\begin{array}{l}\text { 2. Severe anemia } \\
\text { 3. Shock requiring ICU }\end{array}$ & 197 & 33.56 \\
$\quad \begin{array}{l}\text { admissions } \\
\text { 4. Sepsis }\end{array}$ & 23 & 3.9 \\
$\begin{array}{l}\text { 5. Maternal mortality } \\
\begin{array}{l}\text { 6. Patient requiring laporotomy for } \\
\text { ectopic or perforation }\end{array}\end{array}$ & 33 & 5.62 \\
\hline
\end{tabular}


of conception vaginal misoprostol was used to complete the procedure. We had nine cases of ruptured ectopic for which the patient had to undergo emergency laparotomy and partial or total salpingectomy. From this data, it is essential that every patient should undergo a clinical examination and an USG examination before the prescription of the MTP kit.

\section{CONCLUSION}

The need of the hour is for the law to be enacted in an effective way which deems the sale of over the counter abortifacients. Information regarding the contraceptive choices and its advantages should be properly dispersed among the general population to decrease the unmet needs of contraception. Maternal as well as adolescents health clinics should be utilized in a proper manner to drill the information regarding the safe sex practices and advantages of various methods of contraceptive choices as well as emergency contraception in modern practices. We should utilize the media to create awareness specifically targeting the reproductive population regarding the risks, side effects, complications involved with the self-use of MTP pills. LAs per WHO guidelines, the early firsttrimester medical abortion regimen when used safely and adequately are $98.3 \%$ effective with proper supervision6). ${ }^{6}$

When medical abortion was done using buccal misoprostol upto 56 days, the audit demonstrated a success rate of $98.3 \% .^{8}$ All the local pharmacy shops dispersing medical abortion should be strictly regulated.

\section{REFERENCES}

1. Unsafe abortion: global and regional estimates of the incidence of unsafe abortion and associated mortality in 2008, sixth edition;2011. Department of Reproductive Health and Research, World Health Organisation. http://www. who.int/reproductivehealth/publications/unsafe_abortion/9789241501118/en/

2. Singh S, Shekhar C, Acharya R, Moore AM, Stillman M, Pradhan MR. The incidence of abortion and unintended pregnancy in India, 2015. Lancet Global Health 2017;6(11).

3. International consensus conference on non- surgical (medical) abortion in early 1st trimester on issues related to regime and service delivery. Geneva, WHO:2006.

4. Debnath J, Gulati S, Mathur A ET AL. Ectopic pregnancy in the era of medical abortion :are we ready for it? Spectrum of sonographic findings and our experience in a tertiary care service hospital of India. J Obstet Gynecol India. 2013;66(6):388-393.

5. Kaur Sukhwinder B, Singh Sukhminder Jit B, Kaur Gangdeep G, Nirankar S, Anita S, Goraya SPS. Medical abortion : is it a blessing or curse for the developing nations? Srilanka J Obstet Gynaecol. 2011;33:84-90.

6. Thaker RV, Deliwala KJ, Shah PT. Self-medication of abortion pill: women's Health in Jeopardy. NHL J Med Sci. 2014:3(1): 26-31.

7. Sarojini, Ashakiran TR, Bhanu BT, Radhika. Over the counter MTP pills and its impact on women's health. The Journal of Obstetrics and Gynaecology of India. 2017 Feb;67(1):37-41

8. Sivin I, Lichtenberg ES, James T, Kelly C, Cullins V. Effectiveness of medical abortion with mifepristone and buccal misoprostol through 59 gestational days. 2009 Sep;80(3):282286. 